\title{
Roads to Necessitarianism
}

\section{Matthew Mandelkern ${ }^{1}$ (D) . Daniel Rothschild ${ }^{2}$}

Received: 12 August 2019 / Accepted: 13 May 2020 / Published online: 16 June 2020

(C) The Author(s) 2020

\begin{abstract}
We show that each of three natural sets of assumptions about the conditional entails necessitarianism: that anything possible is necessary. Since most agree that this conclusion is obviously false, this shows that at least one member of each set of assumptions must be rejected. All of these assumptions are, however, widely accepted and well-motivated. This creates a puzzle which we leave open.
\end{abstract}

Keywords Logic of conditionals · Triviality results

\section{Introduction}

We show that, given three different sets of assumptions about the logic of conditionals - each of which is very natural and each of which has been defended or assumed by many in the literature-we can prove that necessitarianism is true: that is, that anything which is possible is necessary. For those, like us, disinclined to the conclusion that there are no merely contingent truths, this provides motivation to reject at least one assumption from each set. All of these assumptions are, however, widely accepted and well-motivated. This creates a puzzle which we leave open.

\section{Set-Up}

We work with a standard modal propositional language (with ' $\supset$ ' the material conditional; ' $\equiv$ ' the material biconditional; ' $\wedge$ ' and ' $\neg$ ' conjunction and negation; and

Matthew Mandelkern

matthew.mandelkern@gmail.com

Daniel Rothschild

d.rothschild@ucl.ac.uk

1 All Souls College, Oxford, OX1 4AL UK

2 UCL, London, UK 
and ' $\diamond$ ' necessity and possibility operators), augmented with the two-place connective '>' meant to correspond to the natural language conditional 'If. .. then...' (whether in the indicative or subjunctive mood, which we will not distinguish in our formal language). We assume that the connectives and operators other than ' $>$ ' receive their standard semantics, with the connectives and ' $\neg$ ' given their usual classical Boolean values and ' $\square$ ' and ' $\diamond$ ' receiving a normal modal semantics characterized by the $K$ axioms. (For clarity, in the proofs that follow we distinguish those inferences that follow by the propositional calculus $(P C)$ alone from those that follow from $K$, though $K$ encompasses the propositional calculus.) We assume further that our modal operators satisfy the 5 axiom $(\diamond p \models \square \diamond p)$. We do not make any assumptions about the semantics of ' $>$ ' - since our interest here is what that semantics should, and could, be-apart from the assumption that tautologically equivalent sentences can be substituted salve veritate under ' $>$ '. ${ }^{1}$ We use ' $\Gamma \models p$ ' to mean that in every possible world in every intended model where all the elements of $\Gamma$ are true, $p$ is true (' $p=\models q$ ' means $p \models q$ and $q \models p$ ). Note that a biconditional Deduction Theorem will obtain for our logic: $\Gamma \models(q \supset r)$ iff $\Gamma \cup\{q\} \models r{ }^{2}$

Our three results all start from the assumption that (all uniform substitution instances) of the following are valid:

- Restricted Aristotle's Thesis: $\neg p>p \models \square p$

- Conditional Quodlibet: $\models \square(\neg p) \supset(p>q)$

- Import-Export: $p>(q>r)=\models(p \wedge q)>r$

The first two principles are standard assumptions in the theory of conditionals, both validated, for instance, by the theories of Stalnaker [17], Stalnaker and Thomason [18] and Lewis [11]. Restricted Aristotle's Thesis follows as one half of a standard definition in the logic of conditionals of $\square p$ as $\neg p>p$; the idea is that $\neg p>p$ could only be true if $p$ were in some sense guaranteed to be true no matter what. (The principle is a restricted version of a principle known as Aristotle's Principle, which says that $\neg p>p$ is never true. Most modern theories of the conditional hold that Aristotle's Principle is not valid in general, but that the restricted version here is.) Conditional Quodlibet is closely related in intuitive motivation: it says that if $p$ is necessarily false, then $p>q$ is true for any $q$. In other words, if $p$ is not just false but necessarily false, then anything whatsoever follows from the supposition that $p$ is true.

\footnotetext{
${ }^{1}$ Although this assumption is common to most accounts of conditionals, it is rejected, for example, in Fine's Truthmaker Semantics [2,3].

${ }^{2}$ The Deduction Theorem doesn't hold on certain ways of thinking about entailment in modal logic, but it will hold for systems in which entailment is defined as preservation of truth in all worlds in all intended models, as we have defined it here (rather than as preservation of validity). See Hakli and Negri [6] for helpful discussion; see in particular $\$ 3$ of that paper for a full exposition of the kind of system we have in mind here, and a proof that the Deduction Theorem is valid in that system. We omit corner quotes from our formal language for readability, and omit parentheses when there is no risk of ambiguity. When $\Gamma$ is a singleton $\{q\}$ we write ' $q \models p$ ', and when $\Gamma$ is empty we write ' $\models p$ '.
} 
The third principle says that conditionals of the form $p>(q>r)$ and of the form $(p \wedge q)>r$ are always logically equivalent. Import-Export, while more controversial than our first two principles, is validated by many theories of the conditional (see e.g. McGee [15], Gillies [5], Khoo and Mandelkern [8] and Mandelkern [14]). ${ }^{3}$ There are two main sources of evidence in favor of it which we briefly note here. The first is the felt equivalence of pairs of natural language conditionals which instantiate Import-Export, like the following:

(1) a. If the coin is flipped, then if it lands heads, we'll win.

b. If the coin is flipped and it lands heads, we'll win.

(2) a. If it had rained and there hadn't been a tent, the picnic would have been cancelled.

b. If it had rained, then if there hadn't been a tent, the picnic would have been cancelled.

Pairs like this tend to feel equivalent (see van Wijnbergen-Huitink et al. [19] for experimental evidence to this effect).

The second, more abstract argument for Import-Export comes from Ramsey's [16] suggestion that you should believe $p>q$ iff you believe $q$ after adding $p$ hypothetically to your stock of beliefs. If we iterate this test, we get the result that you should believe $p>(q>r)$ iff you should believe $(p \wedge q)>r$-which in turn suggests that these pairs have the same truth-conditions. So, intuitively, you should believe (1a) just in case, after adding 'the coin is flipped' hypothetically to your beliefs, and after then adding 'it lands heads' hypothetically to your beliefs, you should then believe we'll win; which are the same intuitive conditions of belief as those of (1b). See Arló-Costa [1] for a detailed exposition of this argument.

In sum, all three of our starting principles are well-motivated and widely accepted.

\section{Right Monotonicity}

We now explore three different augmentations of these three core principles, each of which allows us to obtain our absurd result. The first, and simplest, approach takes on board the following principle: ${ }^{4}$

- Right Monotonicity: If $\models p>q$ and $s \models q \supset r$ then $\square s \models p>r$

\footnotetext{
${ }^{3}$ The systems developed in Kratzer [9, 10] are sometimes said to validate Import-Export. On Kratzer's view if-clauses serve as restrictors to implicit or explicit modal operators. Even if we only consider cases in which there are silent modal operators, whether the conditional in Kratzer's view validates Import-Export (or other principles) is not easily determinable without explicit rules governing the distribution of silent modal operators. While Kratzer [10] suggests that in some simple examples her system would validate Import-Export, she does not provide general principles that make the import-export schema valid. As Khoo and Mandelkern [8] and Mandelkern [14] discuss, Gillies' theory in fact only validates a slightly restricted version of Import-Export which maintains equivalence only when the imported/exported sentence is not itself a conditional; this restriction would block the third proof below, but not the first two.

${ }^{4}$ Meta-language 'If. . . then' in these principles should be interpreted materially.
} 
Right Monotonicity encodes the very natural and widely validated assumption that, if $p>q$ is always true; and if every $s$ world which is a $q$-world is also an $r$-world; and if we are at a world where all accessible worlds are $s$-worlds; then, $p>r$ is also true at our world. In other words, if, at any world, all the $p$-worlds relevant to evaluating a conditional are $q$-worlds, and if all the accessible $q$-worlds from our given world are also $r$ worlds, then $p>r$ must also be true at our given world. (We don't mean to commit to any particular semantic analysis of the conditional in this paper; these informal glosses in terms of worlds are, however, neutral across many different analyses, and can be helpful in seeing the motivation for principles like this one.)

Right Monotonicity, together with the three assumptions at the outset, entails that, for any $p, \diamond p \models \square p$. The proof is in an Appendix. ${ }^{5}$

\section{Logical Implication and Logical Ad Falsum}

The second approach, in place of Right Monotonicity, adds two different principles to our starting three:

- Logical Implication: If $p \models q$ then $\models p>q$

- Logical Ad Falsum: If $\models p>q$ and $\models p>\neg q$ then $\models \neg p$

Logical Implication says that, if $p$ entails $q$, then $p>q$ is a logical truth; this encodes the very natural idea that the natural language conditional is bounded from above by entailment. Logical Ad Falsum is a corollary of Restricted Aristotle's Thesis under mild further assumptions, and can be motivated in the same way.

These two principles, in the presence of our three core principles, entail that $\diamond p \models$ $\square p$; the proof, again, is in the Appendix.

\footnotetext{
${ }^{5}$ A slightly different result can be obtained by an even weaker form of monotonicity, plus a second principle:
}

- Weak Right Monotonicity: If $\models p>q$ and $\models q \supset r$ then $\models p>r$

- Just Add $r$ : If $\models p>q$ then $\models(p \wedge r)>(q \wedge r)$

Weak Right Monotonicity is strictly weaker than Right Monotonicity. Just Add $r$ says that if $(p>q)$ is invariably true, then adding the same sentence to the antecedent and consequent should not affect the truth value. We could motivate it as follows: $(r>r)$ is always true: all the relevant $r$-worlds are always $r$ worlds. If $(p>q)$ is also always true, then all the relevant $p$-worlds are always $q$-worlds. But then all the relevant worlds which are both $p$-worlds and $r$-worlds should also be both $q$-worlds and $r$-worlds. Weak Right Monotonicity and Just Add r, together with our three core assumptions, let us argue to the conclusion that $\models \diamond p>\square p$ (this conclusion slightly differs from the main one we focus on here, but is in the same spirit). The proof is left to the reader: the key steps comprise showing that $=\neg p>(p>\neg p)$ in the usual way, from which it follows by Just Add $r$ that $\models(\neg p \wedge \diamond p)>((p>\neg p) \wedge \diamond p)$. Then we show from Restricted Aristotle's Thesis that $\models((p>\neg p) \wedge \diamond p) \supset p$. Weak Right Monotonicity gives us $\models(\neg p \wedge \diamond p)>p$; Import-Export, Weak Right Monotonicity, and Restricted Aristotle's Thesis get us to the conclusion that $=\diamond p>\square p$. 


\section{Nothing Added}

The final approach adds to our three core principles one further principle:

- Nothing Added: If $\models p>q$ then $\models(p>(q>r)) \equiv(p>r)$

Nothing Added is intuitive for roughly the same reason that Logical Implication is. If $(p>q)$ is a logical truth, then $q$ has no intercessionary power, as it were, in a conditional of the form $(p>(q>r)): q$ contributes nothing more beyond what $p$ already contributed. ${ }^{6}$ Once more, Nothing Added in the presence of our three core principles lets us prove that $\nabla p \mid=\square p$; the proof, again, is in the Appendix.

\section{Relation to Gibbard [4]'s Result}

Before concluding, let us situate our results in relation to Gibbard [4]'s famous collapse result. Gibbard showed that Import-Export does not sit well with two other principles. In particular, Gibbard showed that Import-Export, Logical Implication, and Modus Ponens for ' $>$ ' (which says that $\{p, p>q\} \vDash q$ ) together collapse the natural language conditional ' $>$ ' to the material conditional ' $\supset$ '. This collapse is widely taken to be unacceptable, since the natural language conditional appears not to be the material conditional. Gibbard's result, however, does not show that ImportExport on its own leads to the collapse to the material conditional, and indeed, it does not: many non-material theories validate Import-Export. And so Gibbard's result does not on its own show that Import-Export must be rejected. Indeed, many have responded to Gibbard's result by adopting theories which invalidate Modus Ponens for ' $>$ ' and which validate Import-Export instead (see e.g. McGee [15], Kratzer [9], Yalcin [20], Gillies [5] and Khoo [7]).

Unlike Gibbard's results, our results do not rely on Modus Ponens; and we rely on Logical Implication only for the second of our three results. So while, like Gibbard, we show a tension between Import-Export and some other principles, the other principles are very different in the two cases. Of course, taken together with Gibbard's result, our results may be taken to provide evidence against Import-Export; but we will not take a stand on that here. ${ }^{7}$

\section{Conclusion}

In sum, our three core assumptions-Restricted Aristotle's Thesis, Conditional Quodlibet, and Import-Export_-paired either with Right Monotonicity, or with Logical Implication and Logical Ad Falsum, or with Nothing Added, let us prove that anything possible is necessary. From a metaphysical perspective, this would mean

\footnotetext{
${ }^{6}$ See Mandelkern [14] for further discussion.

${ }^{7}$ But see Mandelkern $[12,13]$ for a related result, together with an argument that it does count against Import-Export and an attempt to make sense of the data supporting Import-Export.
} 
that there are no merely contingent truths. From a model-theoretic perspective, this would mean that our system is valid only on solipsistic frames (frames in which every world can access at most itself under the accessibility relation for possibility and necessity). From the perspective of most modern theories of the conditional, this would mean that the natural language conditional ' $>$ ' is no stronger than the material conditional ' $\supset$ ', since most theories of the conditional coupled with a solipsistic accessibility relation will be no stronger than the material conditional. From any perspective, the conclusion seems insupportable. Thus some of these principles must be rejected; we will not try to decide here which ones.

Acknowledgments Many thanks to two anonymous referees for this journal and to Angelika Kratzer for helpful feedback on this paper.

Open Access This article is licensed under a Creative Commons Attribution 4.0 International License, which permits use, sharing, adaptation, distribution and reproduction in any medium or format, as long as you give appropriate credit to the original author(s) and the source, provide a link to the Creative Commons licence, and indicate if changes were made. The images or other third party material in this article are included in the article's Creative Commons licence, unless indicated otherwise in a credit line to the material. If material is not included in the article's Creative Commons licence and your intended use is not permitted by statutory regulation or exceeds the permitted use, you will need to obtain permission directly from the copyright holder. To view a copy of this licence, visit http://creativecommonshorg/licenses/by/4. $0 /$.

\section{Appendix}

\section{A.1 First Proof: Right Monotonicity}

For arbitrary $p$ :

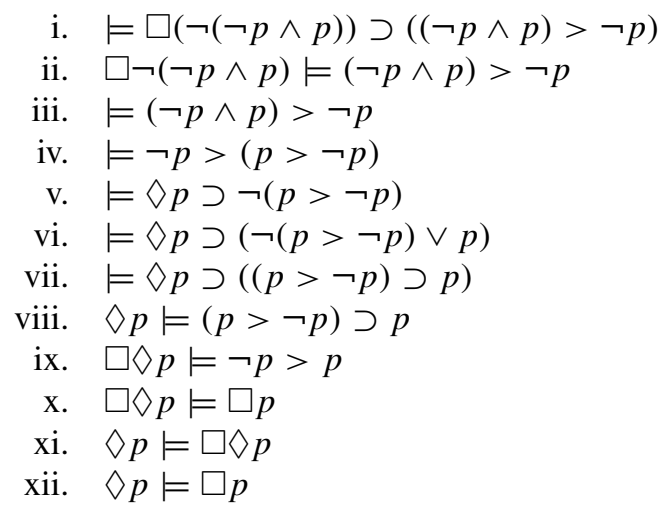

Conditional Quodlibet

Deduction Theorem, (i)

Import-Export, (iii)

Restricted Aristotle's Thesis, PC, K

$P C,(v)$

$P C$, (vi)

Deduction Theorem, (vii)

Right Monotonicity, (iv), (viii)

Restricted Aristotle's Thesis, PC, (ix)

$P C,(\mathrm{x}),(\mathrm{xi})$

\section{A.2 Second Proof: Logical Implication and Logical Ad Falsum}

We note first that the following is entailed by our definition of entailment and our classical semantics for ' $\wedge$ ':

- Monotonicity: If $p \models q$ then $(p \wedge r) \models q$ 
Then, for arbitrary $p$ :
i. $\quad=\square(\neg((\diamond p \wedge \neg p) \wedge p)) \supset(((\diamond p \wedge \neg p) \wedge p)>\neg p)$
ii. $\square \neg((\diamond p \wedge \neg p) \wedge p) \models((\diamond p \wedge \neg p) \wedge p)>\neg p$
Conditional Quodlibet
iii. $\quad=((\diamond p \wedge \neg p) \wedge p)>\neg p$
iv. $=(\diamond p \wedge \neg p)>(p>\neg p)$
v. $\quad=\diamond p \supset \neg(p>\neg p)$
vi. $\diamond p \models \neg(p>\neg p)$
vii. $\diamond p \wedge \neg p \models \neg(p>\neg p)$
viii. $\models(\diamond p \wedge \neg p)>\neg(p>\neg p)$
ix. $\quad=\neg(\diamond p \wedge \neg p)$
x. $\models \diamond p \supset p$
xi. $\quad=\square \diamond p \supset \square p$
xii. $=\diamond p \supset \square \diamond p$
xiii. $\models \diamond p \supset \square p$
xiv. $\diamond p \models \square p$

\author{
Deduction Theorem, (i) \\ Import-Export, (iii)
totle's Thesis, $P C, K$ \\ Restricted Aristotle's Thesis, $P C, K$
Deduction Theorem, (v) \\ Monotonicity, (vi) \\ Logical Implication, (vii) \\ Logical Ad Falsum, (iv), (viii) \\ $P C$, (ix) \\ $K,(\mathrm{x})$ \\ $P C$, (xi), (xii) \\ Deduction Theorem, (xiii)
}

\section{A.3 Third Proof: Nothing Added}

For arbitrary $p$ :
i. $\models \square(\neg(\neg p \wedge p)) \supset((\neg p \wedge p)>\neg p)$
Conditional Quodlibet
ii. $\square \neg(\neg p \wedge p) \models(\neg p \wedge p)>\neg p$
Deduction Theorem, (i)
iii. $\models(\neg p \wedge p)>\neg p$
iv. $\models \neg p>(p>\neg p)$
$K$, (ii)
v. $\models \diamond p \supset \neg(p>\neg p)$
Import-Export, (iii)
vi. $\models \square(\diamond p \supset \neg(p>\neg p))$
Restricted Aristotle's Thesis, PC, K
vii. $\models \square \diamond p \supset \square \neg(p>\neg p)$
viii. $\models \diamond p \supset \square \diamond p$
ix. $\models \diamond p \supset \square \neg(p>\neg p)$
x. $\diamond p \models \square \neg(p>\neg p)$
xi. $\diamond p \models \square \neg(p>\neg p) \supset((p>\neg p)>(\neg p>p))$
$P C$, (vii), (viii)
Deduction Theorem, (ix)
xii. $\diamond p \models(p>\neg p)>(\neg p>p)$
Conditional Quodlibet
xiii. $\diamond p \models((p>\neg p) \wedge \neg p)>p$
$P C,(\mathrm{x}),(\mathrm{xi})$
xiv. $\diamond p \models(\neg p \wedge(p>\neg p))>p$
xv. $\diamond p \models \neg p>((p>\neg p)>p)$
xvi. $\diamond p \models(\neg p>((p>\neg p)>p)) \equiv(\neg p>p)$
xvii. $\diamond p \models \neg p>p$
(xii), Import-Export
(xiii), $P C$
(xiv), Import-Export
(iv), Nothing Added
(xv), (xvi), $P C$
xviii. $\diamond p \models \square p$
Restricted Aristotle's Thesis, (xvii), PC

\section{References}

1. Arló-Costa, H. (2001). Bayesian epistemology and epistemic conditionals: on the status of the exportimport laws. The Journal of Philosophy, 98(11), 555-593. 
2. Fine, K. (2012). Counterfactuals without possible worlds. The Journal of Philosophy, 109, 221-246.

3. Fine, K. (2017). Truthmaker semantics. In Wrigh, B.H.C., \& Miller, A. (Eds.) Blackwell companion to the philosophy of language: Blackwell.

4. Gibbard, A. (1981). Two recent theories of conditionals. In Harper, W.L., Stalnaker, R., Pearce, G. (Eds.) Ifs: conditionals, beliefs, decision, chance, and time (pp. 211-247). Dordrecht: Reidel.

5. Gillies, A. (2009). On truth conditions for If (but not quite only If). Philosophical Review, 118(3), 325-349.

6. Hakli, R., \& Negri, S. (2011). Does the deduction theorem fail for modal logic? Synthese, 187(3), 849-867. https://doi.org/10.1007/s11229-011-9905-9.

7. Khoo, J. (2013). A note on Gibbard's proof. Philosophical Studies, 166(1), 153-164.

8. Khoo, J., \& Mandelkern, M. (2019). Triviality results and the relationship between logical and natural languages. Mind, 128(510), 485-526. https://doi.org/10.1093/mind/fzy006.

9. Kratzer, A. (1981). The notional category of modality. In Eikmeyer, H., \& Rieser, H. (Eds.) Words, worlds, and contexts: new approaches in word semantics (pp. 38-74): de Gruyter.

10. Kratzer, A. (1986). Conditionals. Chicago Linguistics Society, 22(2), 1-15.

11. Lewis, D. (1973). Counterfactuals. Oxford: Blackwell.

12. Mandelkern, M. (2019). Crises of Identity. In Schlöder, J.J., McHugh, D., Roelofsen, F. (Eds.) Proceedings of the 22nd Amsterdam Colloquium (pp. 279-288). University of Amsterdam.

13. Mandelkern, M. (2020). If p, then p! Manuscript, All Souls College, Oxford. https://philpapers.org/ rec/MANIPT-2.

14. Mandelkern, M. (2020). Import-export and 'and'. Philosophy and Phenomenological Research, 100(1), 118-135. https://doi.org/10.1111/phpr.12513.

15. McGee, V. (1985). A counterexample to modus ponens. The Journal of Philosophy, 82(9), 462-471.

16. Ramsey, F.P. (1978/1931). General propositions and causality. In Mellor, D.H. (Ed.) Foundations: essays in philosophy, logic, mathematics and economics (pp. 133-51): Routledge and Kegan Paul.

17. Stalnaker, R. (1968). A theory of conditionals. In Rescher, N. (Ed.) Studies in logical theory (pp. 98112). Oxford: Blackwell.

18. Stalnaker, R.C., \& Thomason, R.H. (1970). A semantic analysis of conditional logic. Theoria, 36(1), 23-42. https://doi.org/10.1111/j.1755-2567.1970.tb00408.x.

19. van Wijnbergen-Huitink, J., Elqayam, S., Over, D.E. (2014). The probability of iterated conditionals. Cognitive Science, 1-16. https://doi.org/10.1111/cogs.12169.

20. Yalcin, S. (2007). Epistemic modals. Mind, 116(464), 983-1026. https://doi.org/10.1093/mind/ fzm983.

Publisher's Note Springer Nature remains neutral with regard to jurisdictional claims in published maps and institutional affiliations. 